\title{
A BACTERIAL ISOLATE FROM THE RHIZOSPHERE OF POTATO (Solanum tuberosum L.) IDENTIFIED AS Ochrobactrum lupini IPA7.2
}

\section{G.L. BURYGIN1, I.A. POPOVA1, K.Yu. KARGAPOLOVA ${ }^{2}$, O.V. TKACHENKO ${ }^{2}$, L.Yu. MATORA', 3, S.Yu. SHCHYOGOLEV1, 3}

\begin{abstract}
${ }^{1}$ Institute of Biochemistry and Physiology of Plants and Microorganisms RAS, Federal Agency of Scientific Organizations, 13, prosp. Entuziastov, Saratov, 410049 Russia, e-mail burygingl@gmail.com, iridecol@yandex.ru, matora_1@ibppm.ru, shegolev_s@ibppm.ru;

${ }^{2}$ N.I. Vavilov Saratov State Agrarian University, 1, Teatral'naya pl., Saratov, 410012 Russia, e-mail kinaschchri@gmail.com, oktkachenko@yandex.ru;

${ }^{3}$ N.G. Chernyshevsky National Research Saratov State University, 83, ul. Astrakhanskaya, Saratov, 410012 Russia

The authors declare no conflict of interests

Acknowledgements:

We thank S.N. Dedysh for assistance in molecular genetic analysis and Yu.M. Serekbaeva for her help in 16S rRNA gene sequencing. We are also sincerely grateful to Prof. Dr Frank Oliver Glöckner for his valuable comments on the use of the resource https://www.arb-silva.de.

Immunofluorescence microscopy was performed at the Symbiosis Center for collective use of scientific equipment (Institute of Biochemistry and Physiology of Plants and Microorganisms RAS, Saratov). DNA preparation, sequencing and assembly of the fragments were made in the Laboratory of microbiology of wetland ecosystems (Institute of Microbiology RAS, Moscow) and ZAO «Evrogen» (Moscow).
\end{abstract}

Received November 14, 2016

\section{Abstract}

We present the results of molecular, genetic, physiological and biochemical investigations of a bacterial isolate from the rhizosphere of potato (Solanum tuberosum L.) as an object to study plant-microbial associativity, used in particular to improve the existing technologies for the production of high-quality planting material by the method of plant culture micropropagation in vitro. To correctly identify the isolate at the species level, we took into account the results of analysis of the current status of prokaryote identification and systematics, reflected in a number of recent reviews. Phylogenetic constructs with strains of the genera Ochrobactrum, Brucella, Ensifer, Mesorhizobium, Rhizobium, and more (closely related to the isolate under study), which were generated by using DNA sequences of $16 \mathrm{~S}$ rRNA genes, revealed the isolate in the immediate surroundings of members of the genus Ochrobactrum. The isolate turned out to be part of the taxonomic group Ochrobactrum anthropi - one of the 1912 taxonomic groups recorded to date, which comprise 6193 prokaryotic species and each include species with coinciding (or almost coinciding) sequences of 16S rRNA genes (http://www.ezbiocloud.net/identify). In accordance with the conceptual propositions formulated in the above-mentioned publications, the species differences within these groups are determined at the level of other molecular genetic (and biochemical and physiological) properties and, with a high probability, by horizontal gene transfer. With account taken of the resulting set of elements of the polyphasic approach, the strain isolated by us was found to be closest to the known type strain $O$. lupini LUP21, which is capable of reinfecting leguminous plants of the genus Lupinus and which carries nodulation and nitrogen fixation genes (nodD and nifH), transferred horizontally into it from rhizobial species. This gave us grounds to identify the isolate being examined as Ochrobactrum lupini IPA7.2.

Keywords: plant-microbe associativeness, Solanum tuberosum L., bacterial isolate, taxonomic identification, 16S rRNA, polyphasic approach, horizontal gene transfer, Ochrobactrum lupini

Symbiosis of microorganisms with plants play a fundamental role in the evolution of life and are of great fundamental and practical interest for the creation of innovative systems of environmentally safe agriculture based on substitution of mineral amendments and pesticides by microbiological preparations [1]. Among the forms of symbiotic interactions, plant-microbial associations occupy an important place with the participation of free-living soil (rhizo)bacteria (plant growth-promoting rhizobacteria - PGPR or plant growth-promoting bacteria PGPB) that stimulate the plant growth. Such associations have a high potential 
as a natural component for modern agrobiotechnologies [2-4]. A good perspective is the creation of plant-microbial associations in vitro based on cellular technologies using mixed cell cultures or plant tissues with bacteria of the PGPB category to obtain high-quality, healthy planting stock of agricultural and ornamental plants with increased resistance ex vitro to adverse environmental conditions [5-7]. The number of bacterial associates is quite large [5-7], but their isolation in situ directly from their habitat and plants, phylogenetic identification and estimation of prospectivity in agrobiotechnology is still of special interest.

Widespread molecular genetic methods, including those based on the use of phylogenetic markers introduced into the standard, the 16S rRNA [8] gene sequenses, are considered sufficiently reliable for solving similar problems. However, in a number of publications in recent years [9-11], more detailed discussion of which may be the subject of a special review, the emerging conceptual and technical problems in the systematics of prokaryotes are analyzed, which should, in our opinion, be taken into account. In particular, it is possible that the studied isolate enters one of the taxonomic groups with coinciding (or almost coinciding) DNA sequences of 16S rRNA genes (http://www.ezbiocloud.net/identify).

This work illustrates some of these problems and concepts on the example of identification of the bacterial isolate from the potato plants rhizosphere of the Nevskii cultivar when screening strains for possible use in reproduction technologies of planting material based on micro-clonal reproduction in vitro [7].

Our goal was to use the sequencing of $16 \mathrm{~S}$ rRNA gene and polyphase approach [10] to identify the studied strain and predict its properties as a promising bacterial associate.

Techniques. IPA7.2 was isolated in 2012 from the homogenate of washed roots of potato (Solanum tuberosum L.) Nevskii cultivar, which grew $3 \mathrm{~km}$ to the south-east of Novopushkinskoye settlement (Engels Region, Saratov Ptovince; N $\left.51^{\circ} 21^{\prime} 28.04^{\prime \prime} \mathrm{E} 46^{\circ} 9^{\prime} 23.82^{\prime \prime}\right)$, at the beginning of tuber formation. Bacteria were isolated on a solid nitrogen-free malate medium $\mathrm{NFb}(\mathrm{N}$-free bromothymol blue medium) of the following composition (g/l): hydroxysuccinic acid - 3.8; $\mathrm{K}_{2} \mathrm{HPO}_{4} \cdot 3 \mathrm{H}_{2} \mathrm{O}-0.4 ; \mathrm{KH}_{2} \mathrm{PO}_{4}-0.4 ; \mathrm{MgSO}_{4} \cdot 6 \mathrm{H}_{2} \mathrm{O}-0,2 ; \mathrm{NaCl}-0.1$; $\mathrm{Na}_{2} \mathrm{MoO}_{4} \cdot 12 \mathrm{H}_{2} \mathrm{O}-0.002 ; \mathrm{FeSO}_{4}$ (in the chelate complex with EDTA) 0.02 ; agar-agar -15 ( $\mathrm{pH}$ was adjusted with $\mathrm{NaOH}$ to 7.0 ), where the culture was subsequently maintained by periodic replanting.

Optimum growth temperature and $\mathrm{pH}$ for the isolate were evaluated in liquid $\mathrm{NFb}$ medium supplemented with $1 \mathrm{~g} / 1 \mathrm{NH}_{4} \mathrm{Cl}$ at $\mathrm{pH} 7.0\left(4^{\circ} \mathrm{C}, 20{ }^{\circ} \mathrm{C}, 28{ }^{\circ} \mathrm{C}\right.$, $\left.35^{\circ} \mathrm{C}, 42{ }^{\circ} \mathrm{C}, 50{ }^{\circ} \mathrm{C}, 60{ }^{\circ} \mathrm{C}\right)$, and $\mathrm{pH} 4.0,5.0,6.0,7.0,8.0,9.0\left(35^{\circ} \mathrm{C}\right)$ by the optical density of the suspension at $\lambda=660 \mathrm{~nm}$ (a spectrophotometer Specord $\mathrm{S}$ 300, Analytik Jena AG, Germany). Urease activity (EC 3.5.1.5) was assessed after 48 hours growth in the medium with $2 \%$ urea as a carbon source $(\mathrm{pH} \mathrm{6.8)}$ in the presence of phenol red, nitrate reduction was estimated in a test with Griss reagent after 7 day growth in NFb supplemented with $\mathrm{KNO}_{3}(2 \mathrm{~g} / \mathrm{l})$. The ability to utilize various organic compounds as a source of carbon and energy was detected by the growth in $0.1 \%$ peptone water with the addition of citric acid, sodium glutamate, mannitol, D-glucose, maltose, sucrose, gluconate, D-mannose and glycerin $(10 \mathrm{~g} / 1 \mathrm{each})$ at $\mathrm{pH} 7.0$.

For specific detection of IPA7.2 on plant roots, the rabbit polyclonal antibodies to $2 \%$ glutaraldehyde-fixed IPA7.2 cells [12] and fluorescent-labeled anti-rabbit antibodies (Alexa Fluor ${ }^{\circledR}$ 532, Invitrogen, USA) were used. Threeday seedlings of white lupine (Lupinus alba L.) and wheat (Triticum aestivum L.) of Saratovskaya 29 cultivar were incubated in a bacterial suspension of IPA7.2 $\left(10^{6}-10^{8}\right.$ cells $\left./ \mathrm{ml}\right)$ for 1 day, and then grew for 3 days in sterile water. Immunofluorescence microscopy was performed using a microscope of Leica LMD7000 
laser dissector set (Leica Mikrosysteme Vertrieb GmbH, Germany) with light filter № $21(545 \pm 12 \mathrm{~nm})$.

Genomic DNA of IPA7.2 was extracted from cells grown on a solid nutrient medium and purified according to the description [13]. The DNA fragments of the $16 \mathrm{~S}$ rRNA gene were subjected to PCR amplification using universal primers $(529 \mathrm{R}, 350 \mathrm{~F}$ and $1492 \mathrm{R})$ under corresponding protocols. The resulting DNA sequence of the 16S rRNA gene of IPA7.2 strain (1403 bp) was deposited in GenBank (https://www.ncbi.nlm.nih.gov/genbank/, accession number KU217325).

Initial set of homologous DNA sequences of the 16S rRNA gene of strains closely related to the IPA7.2 was made using BLASTN technology (https://blast.ncbi.nlm.nih.gov/Blast.cgi?PAGE_TYPE=BlastSearch\&BLAST_SP $\mathrm{EC}=$ TargLociBlast). Besides, in selecting reference strains for phylogenetic analysis their compliance with the SILVA database (https://www.arb-silva.de/) was taken into account. The bioinformatic resources presented on this website were used to compare phylogenetic constructs based on traditional methods and specially developed methods for aligning the $16 \mathrm{~S}$ rRNA sequences [14]. To compare DNA and RNA sequences, algorithms of pairwise and multiple alignment were used (http://www.ezbiocloud.net/taxonomy, http://www.ebi.ac.uk/Tools/msa/, http://embnet.vitalit.ch/software/LALIGN_form.html).

Phylogenetic trees from the sequences of 16S rRNA (https://www.arbsilva.de/aligner) or their genes were constructed using the MrBayes method (http://www.phylogeny.fr/one task.cgi?task_type=mrbayes) and Neighbor Joining from the MEGA v.6 integrated phylogenetic analysis software package (http://www.megasoftware.net/mega.php). For this constructing we applied multiple alignments obtained by the use of the algorithm Clustal Omega (http://www.ebi.ac.uk/Tools/msa/clustalo) and the SINA Alignment Service source (https://www.arb-silva.de/aligner) from SILVA portal (https://www.arb-silva.de).

Results. A distinctive feature of the special methods we used in this work for sequence alignment was their comprising the secondary structure of molecules by means of basic alignment on a large data set for 16S rRNA prokaryotes (about 70 thousand sequences; https://www.arb-silva.de/documentation/release-128).

Blasting of the $16 \mathrm{~S}$ rRNA gene sequence of IPA7.2 isolate using specialized database for bacteria and archaea ribosomal RNA sequences and screening in the SILVA database showed a typical strain Ochrobactrum lupini LUP21 [15] to be the closest to the identified isolate by the total count, the maximum similarity assessment in SILVA and the percentage identity (Table 1). The analysis of fragments after pairwise global and local alignment carried out by two independent methods (LALIGN and EzTaxon) [19] for 16S rRNA sequences of these two strains in the regions with detected differences, showed that along the total length of the IPA7.2 16S rRNA (1403 bp), both sequences practically coincided (99.9\% identity) within addition of two (see Fig. 1, A) and one (see Fig. 1, B) gaps.

\section{Members of the Ochrobactrum anthropi taxonomic group (pairwise identity with sequences of $16 \mathrm{~S}$ rDNA isolate $>98.65 \%$ )}

\begin{tabular}{|c|c|c|c|c|c|}
\hline Typical strain & Reference & Source & GenBank identifier & Identity, \% & Score \\
\hline O. lupini LUP21 & [15] & Lupin Lupinus honoratus C.P. Sm. & NR_042911 & 99.93 & 2586 \\
\hline O. cytisi ESC1 & [16] & $\begin{array}{l}\text { English broom Cytisus scoparius } \\
\text { (L.) Link }\end{array}$ & NR_043184 & 99.86 & 2580 \\
\hline O. anthropi ATCC 49188 & [17] & Clinical samples from a human & NR_074243 & 99.86 & 2580 \\
\hline O. tritici SCII 24 & [18] & $\begin{array}{l}\text { Wheat Triticum aestivum L. soil } \\
\text { and rhizoplane }\end{array}$ & NR_028902 & 99.57 & 2543 \\
\hline
\end{tabular}

However, as per http://www.ezbiocloud.net/identify data, both strains 


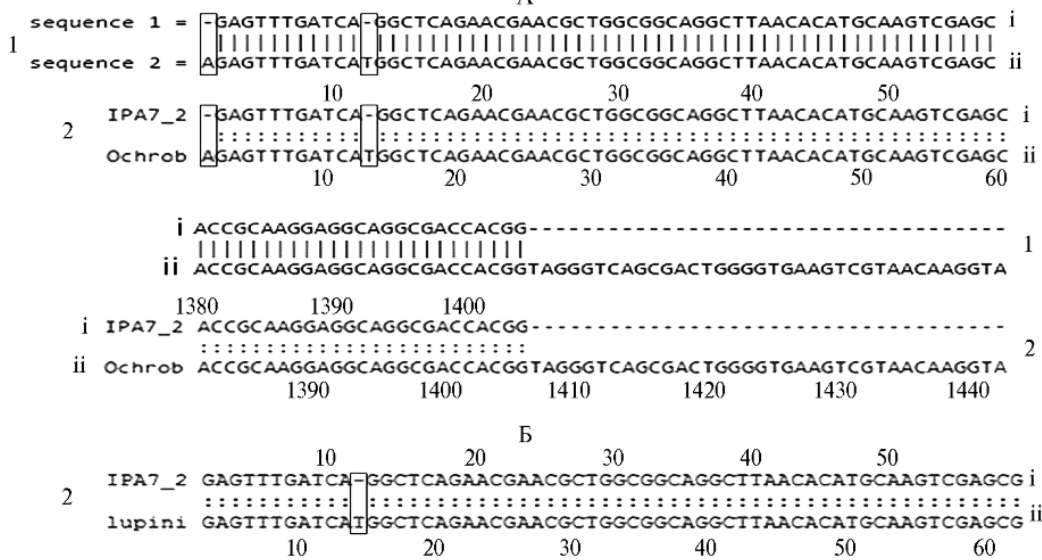

Fig. 1. Fragments of global (A) and local (B) alignment of the 16S rRNA gene sequences of IPA7.2 isolate (i) and the Ochrobactrum lupini LUP21 (ii): 1 - carried out by the method of O.S. Kim et al. [19], 2 - performed in LALIGN program.

should be included in one of 1912 so-called taxonomic groups (i.e. Ochrobactrum anthropi) of 6193 prokaryotes species. Each of these groups comprises the species with coinciding or almost coinciding $16 \mathrm{~S}$ rRNA gene sequences. Their conservativism turned out to be so high that in each group the bacterial species are virtually indistinguishable from each other on this basis and can not be identified by $16 \mathrm{~S}$ rRNA analysis without additional genetic or physiological and biochemical studies. The paper of G.E. Fox et al. [20] was probably one of the first reports of the mentioned phenomenon. The high conservativism in the sequences of 16S rRNA genes in this case leads to a kind of "degeneracy" of an attribute with respect to speciation processes controlled primarily by horizontal gene transfer (HGT) for prokaryotes with open pangenome [9, 10]. Such results, therefore, can serve for detection of xenologes in the genomes of the studied microorganisms, which are responsible for species-specific phenotypic characters [21]. In this context, our results of the multiple alignment (MSA, according to the MUSCLE method, http://www.ebi.ac.uk/Tools/msa/muscle/) and pairwise alignment of the $16 \mathrm{~S}$ rRNA gene sequences for the members of $O$. anthropi group are quite evident. From ten species of this group the members of species $O$. lupini, O. anthropi, O. tritici and $O$. cytisi were the closest to the studied isolate in the pairwise identity of the 16S rRNA gene sequences estimated in the BLASTN program. For them, this identity turned out to be higher than the conventional border of species separation (98.65\%), which was accepted recently [22] (see Table 1).

Our data on the MSA of 16S rRNA genes of $O$. anthropi and the studied isolate showed practical coincidence (including that for IPA7.2) within the accuracy of four bases in three $O$. tritici strains and terminal gaps that do not play a significant role in taxonomic assessments. Taking into account the results of numerous studies of 16S rRNA gene structure in prokaryotes, generalized, for example, by O. Paliy et al. [23], it can be assumed that the observed differences in the region of high conservativeness of the $O$. tritici 16S rRNA gene (at positions 160-163) can be recognized as insignificant sequencing inaccuracy (about $0.3 \%$ of the total length) of $16 \mathrm{~S}$ rDNA in $O$. tritic strains. Note that similar results of MSA in this case were obtained using MAFFT (http://www.ebi.ac.uk/Tools/msa/mafft) and TCOFFEE (http://www.ebi.ac.uk/Tools/msa/tcoffee).

Three of four strains from the $O$. anthropi group (see Table 1) belong to soil bacteria actively interacting with leguminous plants (O. Iupini LUP21, 
O. cytisi $\mathrm{ESC} 1$ ) or living on wheat roots (O. tritici SCII24), and one (O. anthropi ATCC 49188) is clinically isolated from human (blood samples mostly). Since the interspecific index of identity of $16 \mathrm{~S}$ rRNA genes, determined by M. Kim et al. [22] statistically after processing data for 6787 genomes of prokaryotes of 22 taxonomic groups, falls within the range of $<98.65 \%$, this parameter could not be the only sign for assignment of the studied isolate to one of these four species. To solve the problem, we used the results of physiological and biochemical study.

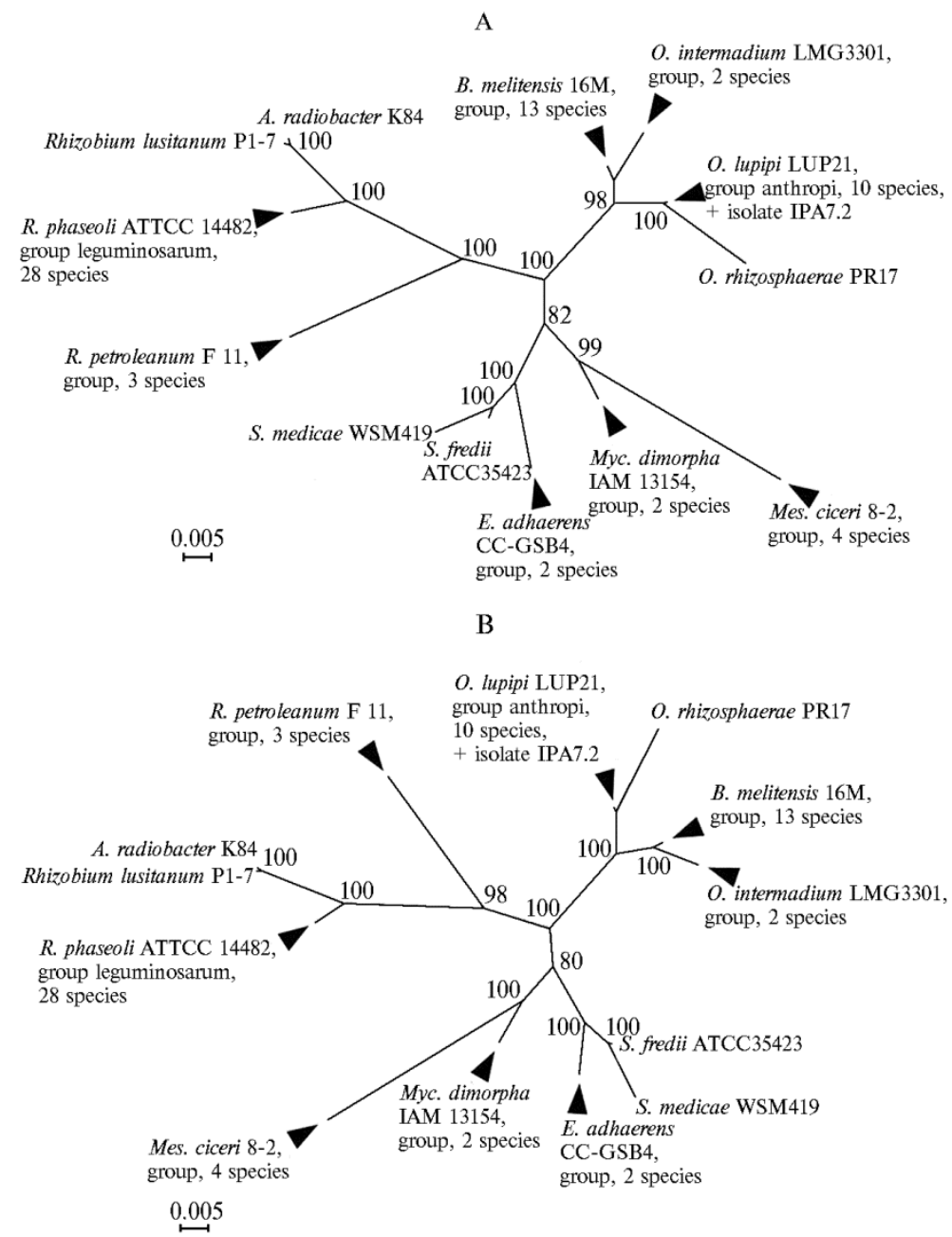

Fig. 2. Phylogram of strains closely related to IPA7.2 isolate, constructed using the method of MrBayes with multiple sequence alignment with Clustal Omega (A) method and SILVA (B). Abbreviated names Agrobacterium, Brucella, Ensifer, Mesorhizobium, Mycoplana, Ochrobactrum, Rhizobium, Sinorhizobium. The numbers show the statistical support of the nodes (Bayesian posteriori probability, \%). Black triangles indicate the entry of organisms with the identified $16 \mathrm{~S}$ rRNA sequences into the corresponding taxonomic groups (http://www.ezbiocloud.net/identify), the number of species in which varies from 2 to 28 .

The taxonomic environment of the studied isolate as a representative of the Rhizobiales at evolutionary distances, reaching intergeneric level, is characterized by the trees (Fig. 2) constructed from MSA which we obtained by two different methods - Clustal Omega (http://www.ebi.ac.uk/Tools/msa/clustalo) (see Fig. 2, A) and offered at the web-resource http://www.arb-silva.de/aligner (see Fig. 2, B). It is reported [24] that the separation at the intergeneric level corresponds to the pairwise identity of the 16S rRNA sequences and their genes 
in the range of $\geq 94.5 \%$. From the initial set of more than 100 sequences (BLASTN, SILVA) satisfying this requirement, we selected 13 reference samples satisfying the following requirements: they were located in typical strains, belonged to the category of complete sequences, or their length was not less than $1380 \mathrm{bp}$. The comparison (see Fig. 2, A and B) shows that the overall topology of the obtained phylogenetic structures practically coincided (up to equivalent mutual positions of the same branches) under two independent methods of alignment with a high statistical support of the nodes (Bayesian posteriori probability). The observed topology was also reproduced using both MSA and the Neighbor Joining method [25] with support of 70-100 \% nodes (at 1000 bootstrapping cycles).

Among the investigated objects, we identified 8 groups with practically identical, according to the conventional border [22, 26], 16S rRNA sequences (> $97 \%$, http://www.ezbiocloud.net/identify) and the number of species from 2 to 28 , combining 64 bacterial species. This more than 5 -fold extends the actual list of species which are closely related to IPA7.2 and nonapparently involved in the phylogenetic trees (see Fig. 2). This type constructions reflect, in fact, the contribution of the network component to the generalized phylogenetic constructions [9], which is due to significant contribution of horizontal gene transfer to speciation within these taxonomic groups. In the set of sequences used, one detects the separation of three clusters (monophyletic groups) which group the members of Brucellaceae, Phyllobacteriaceae and Rhizobiaceae families. The resulted clusterization of species is generally consistent with the data of extended taxonomic studies of the Rhizobiales sequence based on the results of the genome wide DNA sequencing of strains (https://www.patricbrc.org/view/Taxonomy/356\#view_tab=phylogeny).

Information on strains of the close taxonomic environment of IPA7.2, reflected in the annotations and references in GenBank's records, reveal a wide range of habitats for these bacteria (i.e. from the potato rhizosphere, soil samples and rice plants to industrial zones, farm animals and human clinical samples). This testifies to the deep evolutionary connections of the studied isolate with the soil microflora, which is present and functioning in a very diverse ecological niche: from participation in endo- and ectosymbiosis with plants to survival in aggressive ecologically unfriendly environments. There are also a number of evolutionary metamorphoses leading to a very active promotion of individual representatives of the Ochrobactrum genus towards establishing a close relationship with the animal world [17].

In order to properly attribute the IPA7.2 strain to one or another species within the taxonomic group Ochrobactrum anthropi (see Table 1), additional physiological and biochemical studies were required. Consideration of a set of phenotypic, chemotaxonomic and extended genotypic characteristics of strains, which increases the reliability of the description of new taxa (as well as the identification of isolates among existing ones) is called the polyphase approach [10]. Given the majority of the representatives of Ochrobactrum anthropi group belong to soil bacteria actively interacting with plants, we evaluated the ability of the IPA7.2 strain to colonize the roots of lupine and wheat, the macro-partners in symbiosis (association) with plants for $O$. lupini and $O$. tritici representatives. The results of immunofluorescence detection of IPA7.2 cells on the roots of these plants are illustrated in Figure 3. In a series of experiments, it was found that IPA7.2 cells colonize both roots and root hairs of lupine and wheat as multicellular formations - microcolonies or biofilms. At the same time, active colonization of the root surface of both plants with an IPA7.2 strain was noted, indicating that the bacteria had no host plant specificity. 


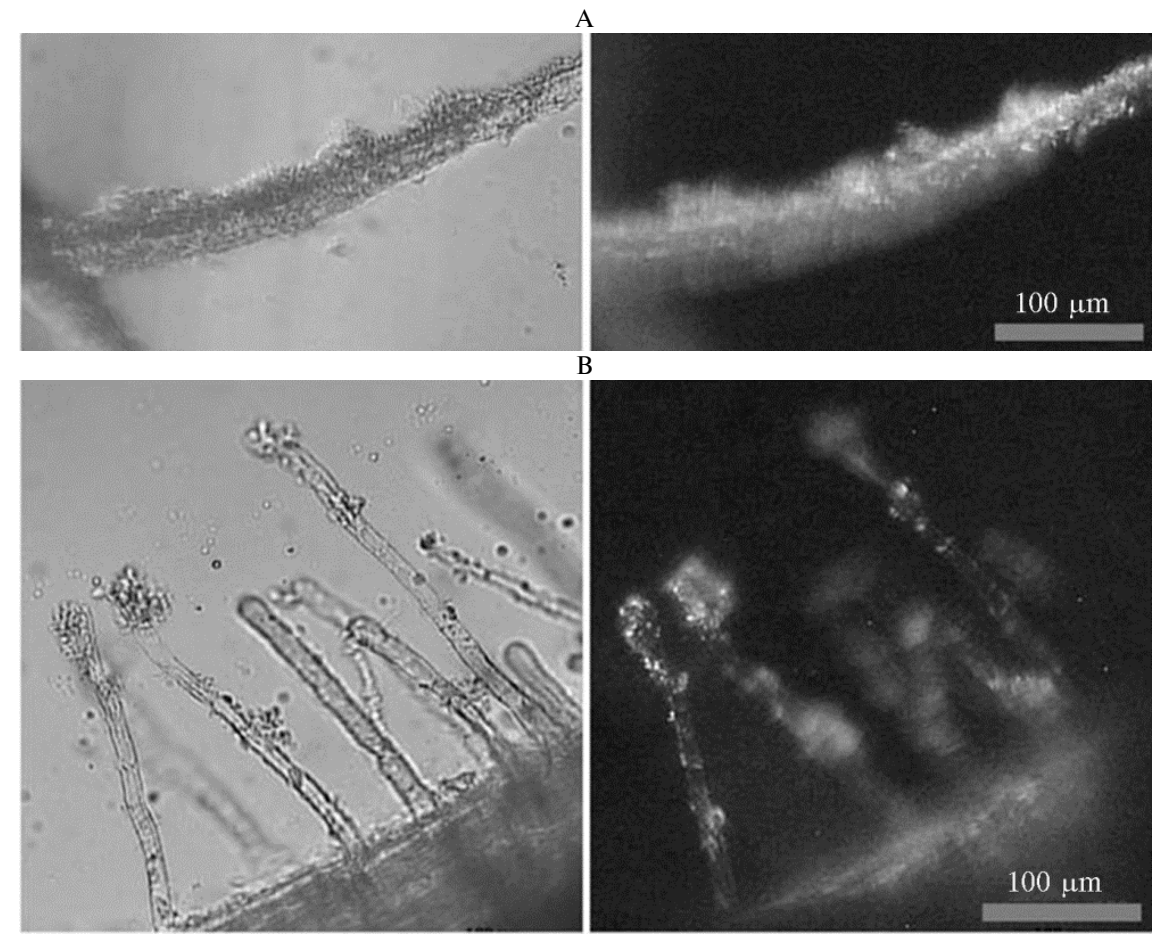

Fig. 3. Immunofluorescence detection of colonization of the lupine white (Lupinus alba L.) roots (A) and wheat (Triticum aestivum L.) Saratovskaya 29 cultivar roots (B) with an identifiable isolate IPA7.2 (Leica LMD7000, Leica Mikrosysteme Vertrieb GmbH, Germany).

The IPA7.2 isolate showed a high biochemical activity, manifested in the ability to grow on medium with malate, citrate, glutamate, mannitol, Dglucose, maltose, sucrose, gluconate and D-mannose, but not glycerin (the best growth characteristics were noted on media with organic acids), on a nitrogen-free $\mathrm{NFb}$ medium with multiple replanting, and also over a wide range of temperatures (from 4 to $42{ }^{\circ} \mathrm{C}$ with an optimum at $35^{\circ} \mathrm{C}$ ) and $\mathrm{pH}$ (from 5.0 to 10.0 with an optimum at $\mathrm{pH} 7.0$ ). The revealed optimum $\mathrm{pH}$ is close to the values ( $\mathrm{pH}$ 7-9) most favorable for $O$. lupini LUP21 cultures.

2. Biochemical characteristics of IPA7.2 isolate and closely related strains from the taxonomic group Ochrobactrum anthropi (pairwise identity with sequences of $16 \mathrm{~S}$ rDNA isolate $>98.65 \%$ )

\begin{tabular}{|c|c|c|c|c|c|}
\hline Trait & IPA7.2 & O. lupini LUP21 & O. anthropi ATCC 49188 & O. tritici SCII24 & O. cytisi $\mathrm{ESC} 1$ \\
\hline Nitrate reduction & - & - & + & + & + \\
\hline $\begin{array}{l}\text { Urease production } \\
\text { after } 48 \text { hours } \\
\text { Assimilation of. }\end{array}$ & + & + & + & + & - \\
\hline gluconate & + & + & + & + & - \\
\hline citrate & + & + & - & - & + \\
\hline D-mannose & + & + & + & - & + \\
\hline
\end{tabular}

When comparing the isolate IPA7.2 and the members of the Ochrobactrum anthropi group (Table 2), it turned out that by the biochemical properties, as well as by the total score in the blasting, the maximum similarity assessed by SILVA method and the established percent identity (see Fig. 1), IPA7.2 most closely corresponds to strain $O$. lupini LUP21. Note that O. lupini LUP21 is a typical strain, it is capable of reinfecting leguminous plants of the Lupinus genus and has nodulation and nitrogen fixation genes (nodD and nifH) obtained from rhizobial species via horizontal transfer [15]. 
As per polyphase approach [10], IPA7.2 strain is the closest to the O. lupini species and can be identified at the current stage of research as O. lupini IPA7.2. On this basis, it may be considered advisable to continue its study as a potential associate (inoculum) in improving plant microclonal propagation in vitro [7].

Thus, the performed phylogenetic studies showed that the members of Ochrobactrum genus are immediate taxonomic environment of IPA7.2 isolate. As per bioinformatic analysis, IPA7.2 belongs to Ochrobactrum anthropi group which comprises 10 species of the genus. This is one of the taxonomic prokaryotic groups, of which each concentrates species with coinciding or almost coinciding $16 \mathrm{~S}$ rRNA gene sequences. Physiological and biochemical tests, along with bioinformatic analysis allow us to identify the isolate as Ochrobactrum lupini IPA7.2. The presence of nodulation and nitrogen fixation genes (nodD and nifH) in a typical species of the group, O. lupini LUP21, makes it possible to predict a bacterial associate properties for IPA7.2, which, however, requires special study.

\section{R E F E R E N C ES}

1. Tikhonovich I.A., Provorov N.A. Simbiozy rastenii i mikroorganizmov: molekulyarnaya genetika agrosistem budushchego [Symbioses plants and microorganisms: molecular genetics of the future agricultural systems]. St. Petersburg, 2009 (in Russ.).

2. B loe mberg G.V., Lugte nberg B.J.J. Molecular basis of plant growth promotion and biocontrol by rhizobacteria. Cur. Opin. Plant Biol., 2001, 4(4): 343-350 (doi: 0.1016/S13695266(00)00183-7).

3. Ves s e y J.K. Plant growth promoting rhizobacteria as biofertilizers. Plant Soil, 2003, 255(2): 571-586 (doi: 10.1023/A:1026037216893).

4. Bashan Y., de-B a shan L.E., Prabhu S.R., He rnande z J.-P. Advances in plant growth-promoting bacterial inoculant technology: Formulations and practical perspectives (1998-2013). Plant Soil, 2014, 378(1-2): 1-33 (doi: 10.1007/s11104-013-1956-x).

5. Bensalim S., Nowak J., Asiedu S.K. A plant growth promoting rhizobacterium and temperature effects on performance of 18 clones of potato. Am. J. Potato Res., 1998, 75(3): 145-152 (doi: 10.1007/BF02895849).

6. Volkogon V.V., Di mova S.B., Mamchu r A.E. Sil's'kogospodars'ka mikrobiologiya (mizhvidomchii tematichnii naukovii zbirnik, Chernigiv, Ukraïna), 2006, 3: 19-25.

7. Tkachenko O.V., Evse eva N.V., B oikova N.V., M a tora L.Yu., Burygi n G.L., L ob a che v Yu.V., S h c hy o g o lev S.Yu. Improved potato microclonal reproduction with the plant growth-promoting rhizobacteria Azospirillum. Agron. Sustain. Dev., 2015, 35(3): 1167-1174 (doi: 10.1007/s13593-015-0304-3).

8. Wo e s e C.R. Bacterial evolution. Microbiol. Rev., 1987, 51(2): 221-271.

9. K u n i n E.V. Logika sluchaya. O prirode $i$ proiskhozhdenii biologicheskoi evolyutsii [Case logic - on the nature and origin of biological evolution]. Moscow, 2014 (in Russ.).

10. O re n A., G a r rity G.M. Then and now: a systematic review of the systematics of prokaryotes in the last 80 years. Antonie van Leeuwenhoek, 2014, 106: 43-56 (doi: 10.1007/s10482-0130084-1).

11. Chun J., Rain e y F.A. Integrating genomics into the taxonomy and systematics of the Bacteria and Archaea. Int. J. Syst. Evol. Micr., 2014, 64(2): 316-324 (doi: 10.1099/ijs.0.054171-0).

12. M to ra L.Yu., Shvartsburd B.I., Shchegolev S.Yu. Immunokhimicheskii analiz O-spetsificheskikh polisakharidov pochvennykh azotfiksiruyushchikh bakterii Azospirillum brasilense. Mikrobiologiya, 1998, 67(6): 815-820 (in Russ.).

13. Ded ys h S.N., P a nik ov N.S., Ti ed je J.M. Acidophilic methanotrophic communities from sphagnum peat bogs. Appl. Environ. Microb., 1998, 64(3): 922-929.

14. Pruesse E., P e plies J., G lö ckner F.O. SINA: Accurate high-throughput multiple sequence alignment of ribosomal RNA genes. Bioinformatics, 2012, 28(14): 1823-1829 (doi: 10.1093/bioinformatics/bts252).

15. Trujillo M.E., Willems A., Abril A., Planchuelo A.-M., Rivas R., Lu d e ca D., Mateos P.F., Martín e z-Molina E., Velázquez E. Nodulation of Lupinus albus by strains of Ochrobactrum lupini sp. nov. Appl. Environ. Microb., 2005, 71(3): 1318-1327 (doi: 10.1128/AEM.71.3.1318-1327.2005).

16. Zurdo-Pineiro J.L., Rivas R., Trujillo M.E., Vizcaíno N., Carrasco J.A., Chamber M., Palomares A., Mateos P.F., M a rtínez-Molina E., Ve lázqu e z E. Ochrobactrum cytisi sp. nov., isolated from nodules of Cytisus scoparius in Spain. Int. J. Syst. Evol. Micr., 2007, 57(4): 784-788 (doi: 10.1099/ijs.0.64613-0).

17. Holmes B., Pop off M., Kiredjan M., Kersters K. Ochrobactrum anthropi gen. 
nov., sp. nov. from human clinical specimens and previously known as group Vd. Int. J. Syst. Bacteriol., 1988, 38(4): 406-416 (doi: 10.1099/00207713-38-4-406).

18. Lebuhn M., Achouak W., Schloter M., Berge O., Meier H., Barakat M., $\mathrm{H}$ a r t m a n n A., H e u li n T. Taxonomic characterization of Ochrobactrum sp. isolates from soil samples and wheat roots, and description of Ochrobactrum tritici sp. nov. and Ochrobactrum grignonense sp. nov. Int. J. Syst. Evol. Micr., 2000, 50(6): 2207-2223 (doi: 10.1099/0020771350-6-2207).

19. Ki m O.S., Cho Y.J., Le e K., Y o o n S.H., Ki m M., N a H., P a r k S.C., J e o n Y.S., L e e J.H., Y i H., Wo n S., Chu n J. Introducing EzTaxon: a prokaryotic 16S rRNA Gene sequence database with phylotypes that represent uncultured species. Int. J. Syst. Evol. Micr., 2012, 62(3): 716-721 (doi: 10.1099/ijs.0.038075-0).

20. Fox G.E, Wi s ot zk e J.D., J urtshyk P., jr. How close is close: 16s rRNA sequence identity may not be sufficient to guarantee species identity. Int. J. Syst. Bacteriol., 1992, 42(1): 166-170 (doi: 10.1099/00207713-42-1-166).

21. Wisniewski-Dye F., Borziak K., Khalsa-Moyers G., Alexandre G., Sukharnikov L.O., Wuichet K., Hurst G.B., McDonald W. H., Robertson J.S., B arbe V., Calte au A., Rouy Z., Mangenot S., Prigent-Combaret C., Normand P., B oyer M., S iguier P., Dess a ux Y., Elmerich C., Condemine G., Krishnen G., Kennedy I., Paterson A.H., Gonzalez V., Mavingui P., Zhulin I.B. Azospirillum genomes reveal transition of bacteria from aquatic to terrestrial environments. PLoS Genetics, 2011, 7(12): e1002430 (doi: 10.1371/journal.pgen.1002430).

22. K i m M., O h H.S., Park S.C., C h u n J. Towards a taxonomic coherence between average nucleotide identity and 16S rRNA gene sequence similarity for species demarcation of prokaryotes. Int. J. Syst. Evol. Micr., 2014, 64(2): 346-351 (doi: 10.1099/ijs.0.059774-0).

23. Paliy O., S hank a r V., S a g ov a -Mare c k ova M. Phylogenetic microarrays. In: Bioinformatics and data analysis in microbiology. Ö.T. Bishop (ed.). Caister Academic Press, Norfolk, 2014: 207-230.

24. Yarza P., Yilmaz P., Pruesse E., Glöckner F.O., Ludwig W., Schleife r K.-H., Whit ma n W.B., Eu z éby J., A mann R., Ros se 11 ó-M ó ra R. Uniting the classification of cultured and uncultured bacteria and archaea using 16S rRNA gene sequences. Nat. Rev. Microbiol., 2014, 12(9): 635-645 (doi: 10.1038/nrmicro3330).

25. H a 11 B.G. Phylogenetic trees made easy: a how-to manual. Sunderland, USA, 2011.

26. Tindall B.J., Rosselló-Móra R., Busse H.-J., Ludwig W., Ka mp fer P. Notes on the characterization of prokaryote strains for taxonomic purposes. Int. J. Syst. Evol. Micr., 2010, 60: 249-266 (doi: 10.1099/ijs.0.016949-0). 